\title{
Fatty Acid Formula Supplementation and Neuromotor Development in Rhesus Monkey Neonates
}

\author{
MARIBETH CHAMPOUX, JOSEPH R. HIBBELN, COURTNEY SHANNON, SHARON MAJCHRZAK, \\ STEPHEN J. SUOMI, NORMAN SALEM, JR., AND JAMES D. HIGLEY \\ Laboratory of Comparative Ethology, NICHD, Poolesville, Maryland 20837, U.S.A. [M.C., C.S., S.J.S.]; \\ Laboratory of Membrane Biochemistry and Biophysics, NIAAA, Rockville, MD, 20852 U.S.A. [J.R.H., \\ S.M., N.S.]; and Laboratory of Clinical Studies, Primate Unit, NIAAA, Bethesda, MD, 20892, U.S.A. [J.D.H.]
}

\begin{abstract}
ABS
Docosahexaenoic acid (DHA) is an omega-3 fatty acid that is
highly concentrated in CNS tissues. Although breast milk con-
tains the fatty acids DHA and arachidonic acid, infant formulas
marketed in North America do not contain these nutrients. The
potential deleterious effects of rearing infants with formulas
devoid of these nutrients was assessed by comparing nursery-
reared rhesus macaque infants (Macaca mulatta) fed standard
formula with infants fed standard formula supplemented with
physiologically relevant concentrations of DHA (1.0\%) and ar-
achidonic acid (1.0\%). Neurobehavioral assessments were con-
ducted on d $7,14,21$, and 30 of life using blinded raters. The
30-min assessment consisted of 45 test items measuring orient-
ing, temperament, reflex capabilities, and motor skills. Plasma
concentrations of DHA in standard formula-fed infants were
significantly lower than those fed supplemented formula or
mother-raised (breast-fed) infants; however, infants fed the sup-
plemented formula exhibited higher arachidonic acid levels than
either mother-reared infants or infants fed standard formula.
Infant monkeys fed the supplemented formula exhibited stronger
\end{abstract}
orienting and motor skills than infants fed the standard formula, with the differences most pronounced during $\mathrm{d} 7$ and 14. This pattern suggests an earlier maturation of specific visual and motor abilities in the supplemented infants. Supplementation did not affect measures of activity or state control, indicating no effect on temperament. These data support the assertion that preformed DHA and arachidonic acid in infant formulas are required for optimal development. (Pediatr Res 51: 273-281, 2002)

\author{
Abbreviations \\ DHA, docosahexaenoic acid \\ AA, arachidonic acid \\ BHT, butylated hydroxytoluene \\ LC-PUFA, long-chain polyunsaturated fatty acid \\ NBAS, Neonatal Behavioral Assessment Scale \\ NICHD, National Institute of Child Health and Human \\ Development
}

NIAAA, National Institute on Alcohol Abuse and Alcoholism
There has been great interest in understanding the role of the long-chain fatty acids in promoting optimal cognitive and neurologic development. Although these nutrients are present in all mammalian breast milks, commercially available infant formulas do not support the tissue requirement for these nutrients in developing infants (1-4). The LC-PUFAs AA (20:4 $\mathrm{n}-6)$ and DHA (22:6 n-3) are selectively concentrated in the cellular membranes of neural and retinal tissues (5). Although human infants are able to synthesize AA and DHA from the precursor molecules linoleic acid (18:2 n-6) and $\alpha$-linolenic

Received January 30, 2001; accepted August 16, 2001.

Correspondence and reprint requests: Maribeth Champoux, Ph.D., NIH Animal Center, P.O. Box 529, Poolesville MD 20837 U.S.A.; e-mail: mc110e@nih.gov

Martek Biosciences Corporation (Columbia, MD, U.S.A.) provided partial financial support for this study. This research was supported by the Intramural Research Programs of the National Institute of Child Health and Human Development and the National Institute of Alcohol Abuse and Alcoholism, National Institutes of Health. acid $(18: 3 n-3)(6-8)$, the rate of synthesis appears to be inadequate to meet the developmental demands of infants (7). In addition, uptake of DHA into brain tissue is more efficient than formation of DHA from $\alpha$-linolenic acid (9). Human breast milk from women in all countries studied delivers both preformed AA and DHA to the developing infant (10). In contrast, commercially available infant formulas in the United States are virtually devoid of DHA and AA but contain the precursor fatty acids 18:2 n6 and 18:3 n3 (11). Thus, formulafed infants exhibit lower levels of AA and DHA in blood and brain tissues relative to their breast-fed counterparts [blood $(12,13)$; brain (1-4)]. These findings have prompted efforts to determine the physiologic benefits of LC-PUFA, particularly DHA, in infant nutrition and development.

Several studies have shown that breast-fed infants exhibit superior performance relative to formula-fed infants on visual task performance (14), psychomotor development (15), intel- 
lectual capability $(16,17)$, and achievement scores (18). However, it is difficult to isolate a deficiency of DHA and AA in formulas as the causal variables in these studies. Comparisons between breast-fed and formula-fed infants include a large number of confounding variables including absence of other nutrients and biologically active factors in formula (19), and differences in maternal factors including socioeconomic status, education, and maternal infant interactions $(20,21)$. In contrast, randomized supplementation trials have been able to isolate AA and DHA as critical variables. These trials have demonstrated that LC-PUFA supplementation can support plasma concentrations of AA and DHA at levels that are comparable to those observed in breast-fed infants and higher than standard formula-fed infants $(11,22,23)$.

Several randomized clinical trials have also provided evidence that LC-PUFA supplementation improves cognitive development and visual function. Studies of both preterm and term infants have reported improvements in mental developmental scores assessed by the Bayley Scales of Infant Development $[(24,25)$ term infants only; however, findings of no effects of supplementation have also been reported, see (26)], the Brunet-Lezine Test (27), the Infant Planning Test (28), and shorter look duration to novel stimuli (29). Several studies have also demonstrated that these improvements persist beyond the period of supplementation $(25,28,30)$ although some do not (31). Improvements in visual acuity and function resulting from LC- PUFA supplementation in both term and preterm infants have also been described $(14,23,32,33)$ and have been supported by meta-analyses $(34,35)$. Outcome measures used to assess cognitive development and visual acuity in infants often have high inherent variability $(36,37)$. Thus, the studies that have described no differences $(38,39)$ must be carefully examined for adequate power, control of the precursor fatty acid composition, and environmental variances of the study populations $(36,40)$. Finally, the concentrations of DHA and AA used for supplementation in the negative studies should be evaluated to determine whether they were adequate $(36,40)$.

One particularly valuable approach that reduces variability in the study population has been the use of nonhuman primates. Among monkeys deprived both pre- and postnatally of LCPUFAs, dietary depletion of n-3 fatty acids causes lower DHA levels in both retina and brain (41). These n-3 fatty aciddeficient animals exhibited deficiencies in visual physiology $(41,42)$, as well as behavioral effects. The n-3 fatty aciddeficient monkeys exhibited polydipsia, polyuria, and more locomotor stereotypies compared with control animals (43, 44). Most previous nonhuman primate models have invoked n-3 fatty acid dietary deficiency throughout the life span, including during pregnancy. In contrast, we conducted this study using a controlled animal model that more closely resembles patterns of LC-PUFA intake in formula-fed human infants; prenatal LC-PUFA sufficiency with postnatal LCPUFA deficiency. In this study we provided a higher amount of supplementation than any prior human infant study [i.e. 0.36 wt \% DHA and $0.72 \mathrm{wt} \%$ AA (25)]. By supplementing the formula with $0.9 \mathrm{wt} \% \mathrm{DHA}$ and $1.0 \mathrm{wt} \% \mathrm{AA}$, we were able to provide a level of supplementation that is physiologically relevant and ecologically valid. For example, this level of supplementation provides DHA and AA levels similar to those found in Japanese mothers' milk (45), and to DHA levels in macaque colostrum (46). Because our groups of animals were small, and the dependent measures had high variability, we endeavored to use concentrations of DHA and AA in the high end of the range of concentrations found in humans. By isolating DHA and AA as variables in two formulas and by rigorously controlling these environmental and nutritional conditions, we are able to test the hypothesis that a DHA and AA insufficiency occurring selectively during the postnatal period would affect neonatal behavioral outcomes.

We used a neurodevelopmental battery specifically designed to test nonhuman primate infants (47) to assess the effects of formula supplementation on neonatal behavioral development. The instrument used, a nonhuman primate adaptation of the NBAS (48), is sensitive to a variety of intrinsic and environmental factors in primate neonates $(47,49-53)$. The advantages of studying nonhuman primate infants include the similarity of physiologic and basic behavioral characteristics to human infants, the ease of access to subjects for repeated testing, and the close relatedness to humans. In addition, environmental conditions were strictly controlled in the nursery, to eliminate confounding factors such as maternal diet or infant treatment. To the best of our knowledge, this is the first study comparing LC-PUFA-supplemented and -unsupplemented formula-fed infants on NBAS outcomes.

\section{METHODS}

\section{Subjects}

Twenty-eight nursery-reared rhesus macaque infants $(\mathrm{Ma}$ caca mulatta) served as study subjects. The study was conducted using three age cohorts for 3 consecutive y. Cohorts 1 and 2 each contained eight infants; cohort 3 consisted of 12 infants. In each cohort, half the infants were provided standard infant formula (described below), and half were fed the standard formula supplemented with a DHA/AA blend. The study was conducted in accordance with regulations governing the care and use of laboratory animals, and was approved by the NICHD and NIAAA Animal Care and Use Committees.

The sample size of 28 infants was derived based on the following considerations. We reviewed previous data from 97 nursery-reared infants from six birth cohorts (1991-1996) to obtain SD measures on each day for each of the dependent measures. The standard deviations for each cluster, averaged across test days, ranged from 0.31 to 0.58 . In a previous study examining genotypic differences on these neonatal assessment outcomes (52), for two of the dependent measures a mean difference of 0.44 was obtained in each case. Although there were no mean differences between genotype groups for the other two dependent measures, for the purpose of this study we assumed a potential mean difference of 0.44 for these measures as well. With an expected power of $80 \%$, an alpha error of 0.05 , and an SD of 0.58 (the largest SD of the four dependent measures from the historical data), the projected sample size to detect a statistically significant effect would be 27 animals. Because we rear our nursery animals in groups of four we could have elected to include either 24 or 28 animals in the 
study. Concerns about the potential genetic variability resulting from using animals from two facilities prompted us to include the larger number of monkeys in the study. This sample size is comparable to those used in prior studies using this neonatal assessment in between-group comparisons to assess genetic and environmental effects on behavior [e.g. 23 infants (49); 42 infants (52)].

\section{Housing}

Infants were separated from their mothers at birth and reared in a neonatal nursery according to previously published procedures (54). From d 1 through 14 of age, animals were individually housed in $51 \times 38 \times 43$-cm plastic cages. Each cage contained a $25-\mathrm{cm}$-high inanimate surrogate mother composed of a $16.5-\mathrm{cm}$-circumference polypropylene cylinder anchored to an $11.5-\mathrm{cm}$-wide circular metal base by a flexible metal component that allowed the surrogate to rock. The surrogate mother was covered with an inner layer consisting of an electric heating pad, and the heating pad was covered with fleece fabric. Loose pieces of fleece fabric, which was typically used as a blanket, covered the floor of the cage. The internal temperature of the cage was maintained at approximately $27^{\circ} \mathrm{C}$. Infants could see and hear, but not physically contact, other infants. At $15 \mathrm{~d}$ of age, the heating pads were removed and the infants were moved with their fleece and surrogates into individual wire mesh cages measuring $64 \times 61 \times 76 \mathrm{~cm}$. As in the earlier housing condition, animals were in visual, auditory, and olfactory, but not tactile, contact with other infants. At approximately d 37 of age, animals entered social groups with similar-aged peers. Lights were on in the nursery from $0700 \mathrm{~h}$ to $2100 \mathrm{~h}$. Room temperature was maintained between $22^{\circ}$ and $26^{\circ} \mathrm{C}$, and humidity was maintained at 50 to $55 \%$.

\section{Feeding}

The standard formula was composed of a 1:1 mixture of Similac (Ross Laboratories, Columbus, OH, U.S.A.) and a commercial monkey formula (Primilac, Bio-Serv, Inc., Frenchtown, NJ, U.S.A.). The supplemented formula consisted of $1 \mathrm{~L}$ of standard formula with $1 \mathrm{~mL}$ of DHA/AA (46\% DHASCO and 54\% ARASCO, Martek Biosciences Co., Columbia, MD, U.S.A.) blended in with a hand mixer. Supplemented formula was mixed as needed, at least once per day. Animals were hand-fed until they were old enough to independently feed themselves (usually by d 3 of life). Between $0800 \mathrm{~h}$ and $2000 \mathrm{~h}, 50 \mathrm{~mL}$ of formula was provided, and formula intake was assessed at 2-h intervals. Animals were provided formula until 6 mo of age. Small pieces of monkey chow (Purina, Allied Mills, Chicago, IL, U.S.A.) were provided daily to the monkeys from d 14. Fatty acid composition of monkey chow is provided in Table 1. Chow contained DHA and AA at higher concentrations than formula, although well below rhesus milk. However, it is unlikely that chow consumption was a significant factor in the study of 7- to 30-d-old infants, as nursery infants rarely consume monkey chow at this age. There is no compelling a priori reason to hypothesize differential chow consumption by the older infants in the different formula feeding conditions.
Table 1. Fatty acid composition of monkey chow

$\begin{array}{lr}\text { Total fatty acids } & 12,938 \\ \text { Saturated } & \\ 14: 0 & 732 \\ 16: 0 & 2,336 \\ 18: 0 & 1,026 \\ \text { Monounsaturated } & \\ 14: 1 & 18 \\ 16: 1 & 201 \\ 18: 1 \mathrm{n} 9 & 3,612 \\ 18: 1 \mathrm{n} 7 & 237 \\ \text { Polyunsaturated } & \\ 18: 2 \mathrm{n} 6 & 4,275 \\ 18: 3 \mathrm{n} 6 & 3 \\ 20: 3 \mathrm{n} 6 & 6 \\ 20: 4 \mathrm{n} 6 & 16 \\ 22: 4 \mathrm{n} 6 & 5 \\ 22: 5 \mathrm{n} 6 & 3 \\ 18: 3 \mathrm{n} 3 & 256 \\ 20: 5 \mathrm{n} 3 & 41 \\ 22: 6 \mathrm{n} 3 & 35\end{array}$

Results are in micrograms per gram $(n=3)$.

\section{AA and DHA Content of Formula/Milk}

Formula samples were collected for measurement of LCPUFA levels, and, for comparison purposes, samples of rhesus breast milk were also obtained. Supplemented formula $(n=7)$ and standard $(n=7)$ formulas were sampled on three separate occasions. Samples were removed directly from the refrigerated containers holding the premixed, ready-for-consumption formulas. Samples of rhesus monkey milk were collected from four females from other research protocols at the Laboratory of Comparative Ethology. All mothers were nursing infants at the time of sample collection; ages of infants ranged from 2 to 6 mo. Mothers were anesthetized with $15 \mathrm{mg} / \mathrm{kg}$ ketamine hydrochloride intramuscularly; samples were collected by gently manually expressing approximately $2 \mathrm{~mL}$ of milk into a plastic vial. Milk and formula samples were stored at $-70^{\circ} \mathrm{C}$ until analysis.

After collection throughout the study, the supplemented formula contained the highest concentration of AA of all tested samples $(1.0 \pm 0.4 \mathrm{wt} \%)$; rhesus breast milk contained intermediate levels $(0.2 \pm 0.1 \mathrm{wt} \%)$, and standard formula contained very small amounts of AA $(0.04 \pm 0.006 \mathrm{wt} \%)$. These three groups differed $(H=20.8, p<0.0001)$ with KruskalWallis testing. DHA was undetectable in standard formula; supplemented formula contained $1.0 \pm 0.4 \mathrm{wt} \%$ DHA and mothers' milk $0.4 \pm 0.1 \mathrm{wt} \%$ DHA. The DHA weight percent differed when comparing mothers' milk and standard formula $(U=88.0 ; p<0.0003)$ using the Mann-Whitney $U$ test. The concentration of total fatty acids was higher in breast milk $(61.7 \pm 26.1 \mathrm{mg} / \mathrm{mL})$ compared with both standard $(16.5 \pm 2.5$ $\mathrm{mg} / \mathrm{mL}, U=87.9, p<0.0004)$ and supplemented formulas $(16.7 \pm 2.5 \mathrm{mg} / \mathrm{mL}, U=87.9, p<0.0004)$. Table 2 contains a detailed description of fatty acid contents of breast milk, supplemented formula, and unsupplemented formula.

\section{Differences among Replications}

Procedures were identical among replications with the following exceptions: in the first year of the study, subjects were 
Table 2. Fatty acid composition of breast milk, standard, and supplemented infant formulas

\begin{tabular}{lccc}
\hline $\begin{array}{c}\text { Fatty acid } \\
(\mathrm{wt} \%)\end{array}$ & $\begin{array}{c}\text { Standard formula } \\
(n=7)\end{array}$ & $\begin{array}{c}\text { Supplemented formula } \\
(n=7)\end{array}$ & $\begin{array}{c}\text { Breast milk } \\
(n=11)\end{array}$ \\
\hline $8: 0$ & $1.9 \pm 0.1$ & $1.8 \pm 0.05$ & $3.2 \pm 1.0^{* \dagger}$ \\
$10: 0$ & $1.6 \pm 0.03$ & $1.6 \pm 0.03$ & $4.1 \pm 1.5 * \dagger$ \\
$12: 0$ & $13.6 \pm 1.4$ & $12.7 \pm 0.9$ & $1.2 \pm 0.5 * \dagger$ \\
$14: 0$ & $5.9 \pm 0.6$ & $6.2 \pm 1.4$ & $1.5 \pm 0.3 * \dagger$ \\
$16: 0$ & $11.5 \pm 0.8$ & $11.8 \pm 2.2$ & $13.4 \pm 10.7 \dagger$ \\
$18: 0$ & $4.2 \pm 0.2$ & $3.9 \pm 0.9$ & $11.9 \pm 8.7 * \dagger$ \\
$20: 0$ & $0.3 \pm 0.0$ & $0.3 \pm 0.0$ & $1.3 \pm 1.7$ \\
$22: 0$ & $0.3 \pm 0.1$ & $0.3 \pm 0.0$ & $2.7 \pm 3.7$ \\
$16: 1$ & $1.0 \pm 0.1$ & $1.1 \pm 0.1$ & $3.6 \pm 0.9 * \dagger$ \\
$18: 1 \mathrm{n} 9$ & $29.7 \pm 5.0$ & $28.2 \pm 8.8$ & $27.8 \pm 1.7$ \\
$18: 1 \mathrm{n} 7$ & $0.9 \pm 0.1$ & $4.0 \pm 9.2$ & $2.2 \pm 1.7$ \\
$20: 1 \mathrm{n} 9$ & $0.2 \pm 0.01$ & $0.2 \pm 0.1$ & $0.5 \pm 0.3 * \dagger$ \\
$24: 1 \mathrm{n} 9$ & $0.1 \pm 0.01$ & $0.1 \pm 0.003$ & $0.1 \pm 0.1$ \\
$18: 2 \mathrm{n} 6$ & $27.4 \pm 3.4$ & $25.8 \pm 2.4$ & $15.7 \pm 12.5$ \\
$18: 3 \mathrm{n} 6$ & $0.03 \pm 0.008$ & $0.1 \pm 0.0 \dagger$ & $0.04 \pm 0.04$ \\
$20: 2 \mathrm{n} 6$ & $\mathrm{ND}$ & $\mathrm{ND}$ & $0.3 \pm 0.1 * \dagger$ \\
$20: 3 \mathrm{n} 6$ & $\mathrm{ND}$ & $\mathrm{ND}$ & $0.3 \pm 0.1 * \dagger$ \\
$20: 4 \mathrm{n} 6$ & $0.04 \pm 0.006$ & $1.0 \pm 0.4 \dagger$ & $0.2 \pm 0.1 * \dagger$ \\
$22: 4 \mathrm{n} 6$ & ND & ND & $0.1 \pm 0.04 * \dagger$ \\
$22: 5 \mathrm{n} 6$ & $\mathrm{ND}$ & ND & $0.1 \pm 0.04 * \dagger$ \\
$18: 3 \mathrm{n} 3$ & $2.0 \pm 0.5$ & $2.1 \pm 0.7$ & $0.7 \pm 0.5 * \dagger$ \\
$20: 5 \mathrm{n} 3$ & ND & $0.1 \pm 0.1 \dagger$ & $0.2 \pm 0.05^{*} \dagger$ \\
$22: 5 \mathrm{n} 3$ & $\mathrm{ND}$ & $0.02 \pm 0.01 \dagger$ & $0.2 \pm 0.1 * \dagger$ \\
$22: 6 \mathrm{n} 3$ & $\mathrm{ND}$ & $1.0 \pm 0.4 \dagger$ & $0.4 \pm 0.1 * \dagger$ \\
\hline & & &
\end{tabular}

$* p<0.01$ compared with supplemented formula.

$\dagger p<0.01$ compared with the standard formula.

All comparisons used Mann-Whitney nonparametric testing.

ND, not detected.

obtained opportunistically and it was not possible to match groups for sex or birth weight. The standard-formula group in cohort 1 contained two males and two females; the supplemented-formula group consisted of three males and one female. In the second and third replications a larger subject pool was available, and animals were matched for sex and birth weight among groups. Cohorts 2 and 3 therefore contained equal numbers of males and females in the standard-formula and supplemented-formula conditions. Animals in the first cohort were born at the Laboratory of Comparative Ethology (NICHD) breeding facility in Poolesville, MD, U.S.A., and the animals in cohorts 2 and 3 were obtained from Laboratory Animal Breeders Services (LABS, Yemassee, SC, U.S.A.).

\section{Neonatal Assessment}

A 30-min developmental assessment battery was administered on $\mathrm{d} 7,14,21$, and 30 of life. This test was derived from the Brazelton Neonatal Assessment Scale used in human newborns $(48)$ and has been described in detail elsewhere $(47,49)$. Raters were trained to a reliability criterion of 0.90 before collecting data (Pearson product-moment correlation) according to a rigorous training protocol (55). The author of the assessment directly trained M.C. to a criterion of reliability exceeding 0.90; M.C. then trained additional raters. All individuals were highly trained, performing the assessment reliably on both mother- and nursery-reared infants for more than $1 \mathrm{y}$ before the onset of this study. Two individuals who were blind to the experimental condition of the animals conducted the majority of the assessments (99 of 111 assessments; 89\%). Two additional observers who were not blind to the experimental treatment conducted 12 assessments: nine in cohort 1 and three in cohort 2. This circumstance was unavoidable owing to the necessity to obtain all assessments on the appropriate day of life, and the resulting inability of the blind observers to perform all the required assessments on any given day. The nonblinded observers were unaware of the experimental hypotheses being tested, and performed seven assessments on control infants and five assessments on supplemented infants. Assessment scores from blinded and nonblinded observers did not differ significantly for either feeding condition or any of the clusters. One supplemented-formula infant in cohort 1 was not tested on d 21 owing to scheduling conflicts.

The test was administered between $1100 \mathrm{~h}$ and $1300 \mathrm{~h}$. Test items were presented in invariant order following a predetermined sequence. Initially, orientation abilities and attention to visual and auditory stimuli were assessed. This was followed by measurement of a variety of reflex and sensorimotor functions, including tactile responsiveness, postural adjustment capabilities, and muscle tone. In addition, the response to a brief challenge was assessed during a 6-min session in which the animal was placed into a small cage (see above for description of the housing cage used during $\mathrm{d} 1-14$ ). The test cage was empty except for an absorbent liner pad and the stimulus used for the visual orienting items. The cage was not unfamiliar for the animals, but was devoid of comfort items such as blankets, toys, surrogates, and bottles. The first minute of the 6-min session was devoted to obtaining a count of emitted vocalizations; a 5-min focal behavioral observational period then ensued in which behavioral inactivity, fine and gross motor activity, and coordination were assessed. Temperament characteristics were rated after administration of the orienting and neuromotor items, based on the infant's behavior throughout the test period. These measures included the tester's impressions of the animal's fearfulness, tendency to struggle, consolability, irritability, ability to self-soothe, cuddliness, and overall state of arousal. With the exception of 60-s vocalization count, all items were scored on a scale of $0-2$, with scores of 0.5 and 1.5 allowable. As in previous studies (49), some of the individual test items were aggregated into four clusters representing orientation, state control, motor maturity, and activity. Cluster constituents are listed in Table 3.

\section{Blood Collection}

Blood samples were collected for determination of plasma DHA and AA levels. Samples were obtained from all study infants at $2,4,8,12,16$, and $20 \mathrm{wk}$ of age. For comparison purposes, equivalent samples were also collected from 14 mother-reared (breast-fed) infants from the breeding colony: four mother-reared infants each were sampled in y 1 and 2, and six infants were sampled in y 3 , of the study. Mother-reared infants were matched to study infants on sex of infant and birth date of infant, as closely as possible. All samples were collected between $1130 \mathrm{~h}$ and $1430 \mathrm{~h}$. Animals were immobilized with ketamine hydrochloride (intramuscularly, $15 \mathrm{mg} / \mathrm{kg}$ ) before sample collection. Two milliliters of blood was collected 
Table 3. Neonatal assessment item definitions

\begin{tabular}{|c|c|}
\hline Item & Definition \\
\hline \multicolumn{2}{|l|}{ Orientation cluster } \\
\hline Visual orientation & $\begin{array}{l}\text { Eyes oriented toward toy (Mickey Mouse face) } \\
\text { held in four positions in infant's periphery }\end{array}$ \\
\hline Visual following & $\begin{array}{l}\text { Eyes following moving toy (same as above) in } \\
\text { horizontal and vertical directions }\end{array}$ \\
\hline Duration of looking & $\begin{array}{l}\text { Examiner rating of length of looks on orienting } \\
\text { items }\end{array}$ \\
\hline Attention & Examiner rating of attention on orienting items \\
\hline \multicolumn{2}{|l|}{ State control cluster } \\
\hline Irritability & $\begin{array}{l}\text { Amount of distress noted during the entire } \\
\text { examination }\end{array}$ \\
\hline Consolability & Ease of consoling infant following distress \\
\hline Predominant state & State of infant during examination \\
\hline Struggle & Amount of squirming during examination \\
\hline \multicolumn{2}{|l|}{ Motor maturity cluster } \\
\hline Coordination & $\begin{array}{l}\text { Quality of motor activity rated during the } \\
\text { 5-min observation period }\end{array}$ \\
\hline Head posture prone & Ability to hold head up when held in air prone \\
\hline Head posture supine & Ability to hold head up when held in air supine \\
\hline $\begin{array}{l}\text { Labyrinthian } \\
\text { righting }\end{array}$ & $\begin{array}{l}\text { Realignment of head when body is tilted } 45^{\circ} \\
\text { sideways }\end{array}$ \\
\hline Response speed & Examiner rating of speed of responding \\
\hline \multicolumn{2}{|l|}{ Activity cluster } \\
\hline Passive & $\begin{array}{l}\text { Duration of time spent inactive during the } \\
5 \text {-min observation period }\end{array}$ \\
\hline Coordination & $\begin{array}{l}\text { Quality of motor activity rated during the } \\
\text { 5-min observation period }\end{array}$ \\
\hline Motor activity & $\begin{array}{l}\text { Observation of amount of motor activity during } \\
\text { the 5-min observation period }\end{array}$ \\
\hline $\begin{array}{l}\text { Spontaneous } \\
\text { locomotion }\end{array}$ & $\begin{array}{l}\text { Quality of locomotion rated during the 5-min } \\
\text { observation period }\end{array}$ \\
\hline
\end{tabular}

from the femoral vein into an EDTA anticoagulant-treated Vacutainer collection tube. After centrifugation, a $500-\mu \mathrm{L}$ aliquot of plasma was placed into a plastic vial and stored at $-70^{\circ} \mathrm{C}$ until assay.

\section{Analysis of AA and DHA Content of Plasma and Formula/Milk}

Fatty acids were extracted from $100 \mu \mathrm{L}$ of plasma using a modification of the Folch method (56). Samples were aliquoted into $2 \mathrm{~mL}$ of $\mathrm{CHCl}_{3}, 1 \mathrm{~mL}$ of BHT-MeOH, and a known quantity of 23:0 fatty acid as an internal standard. One milliliter of $0.2 \mathrm{M} \mathrm{Na}_{2} \mathrm{HPO}_{4}$ was added after a brief vortexing. The samples were capped under nitrogen and vortexed again. After centrifugation, the $\mathrm{CHCl}_{3}$ solvent layer was extracted and placed under nitrogen stream. The extraction procedure was repeated a second time with an additional $2 \mathrm{~mL}$ of $\mathrm{CHCl}_{3}$. The two $\mathrm{CHCl}_{3}$ layers were combined and evaporated to dryness under nitrogen. Samples were methylated with $\mathrm{BF}_{3}-\mathrm{MeOH}$ for 60 min (57). Gas chromatography was performed on the methylated samples using a Hewlett Packard 5890 series II with a flame ionization detector, an autosampler, and a DBFFAP capillary column ( $\mathrm{J} \& \mathrm{~W}$ Scientific, Folsom, CA, U.S.A.), using previously described methods (58). Peaks were identified using authentic standards (NuCheck Prep, MN, U.S.A.). Fatty acids were quantified by comparison to peak areas of the 23:0 internal standard. The BHT peak was selectively excluded by adjusting peak integration variables.
Fatty acid compositions of milk and formula samples were determined without extraction using direct transesterification methods (59). All samples were appropriately protected from UV light during storage and protected from oxidation during analysis with the use of nitrogen blankets and cold conditions. A $40-\mu \mathrm{L}$ quantity of each milk or formula sample was aliquoted into $2 \mathrm{~mL}$ of 4:1 methanol-hexane solvent containing $50 \mu \mathrm{g} / \mathrm{mL}$ BHT and $10 \mu \mathrm{g}$ of 23:0 fatty acid internal standard. After addition of sample, tubes were vortexed briefly and $200 \mu \mathrm{L}$ of acetyl chloride reagent was added slowly, over ice. Sample reaction mixtures were then heated at $100^{\circ} \mathrm{C}$ for $60 \mathrm{~min}$. After heating, the reaction mixtures were neutralized with $5 \mathrm{~mL}$ of $6 \% \mathrm{~K}_{2} \mathrm{CO}_{3}$ buffer, and the hexane layers were extracted for gas chromatographic analysis. Gas chromatography was performed on the methylated samples using the same equipment and methods as the plasma fatty acid quantification procedures (see above). The within run and between run coefficients of variation were $0.3 \%$ and $1.0 \%$, respectively.

\section{Statistical Analysis}

Milk and formulas. Comparison among breast milk and formulas was conducted using nonparametric Mann-Whitney $U$ test, unpaired two-group comparisons, and Kruskal-Wallis three-group comparisons.

Plasma samples. Initial univariate analyses of variance were conducted with cohort and condition (control, supplemented, mother-reared) as between-groups factors and time point (wk 2 , wk 4) as a within-groups factor. Because there were some missing data points owing to inability to collect sufficient blood for assay, univariate ANOVAs, which compensate for missing data, were conducted using the statistical program SuperANOVA (Abacus Concepts, Berkeley, CA, U.S.A.). Because initial analyses revealed statistically significant effects of cohort for both AA $\left(F_{2,31}=74.79 ; p<0.001\right)$ and DHA $\left(F_{2,31}\right.$ $=69.65 ; p<0.001)$, additional analyses were conducted. AA and DHA values were converted to standard scores within each cohort; ANOVAs were then conducted on the standardized scores.

Neonatal assessments. One male infant from cohort 3 was removed from analyses because, even though he had been allocated to the standard-formula group, he had not been removed from his mother until d 3 postpartum. Therefore, all analyses were conducted comparing 13 standard-formula infants with 14 supplemented-formula infants. Mother-reared comparison infants were not incorporated into these analyses, as substantial rearing condition differences between motherand nursery-reared infants on the response to testing could potentially confound the comparison with supplemented formula-fed nursery-reared infants.

Data from each of the four clusters were analyzed separately. Data were analyzed by three-way mixed design ANOVAs with formula type (standard, supplemented) and cohort (y 1, y 2, y 3 ) as between-group factors and test day (d 7, d 14, d 21, d 30) as within-groups factors. The statistical program SuperANOVA (Abacus Concepts) was used for all analyses. 


\section{RESULTS}

$A A$ and $\mathrm{DHA}$ content of plasma. Analyses of plasma AA and DHA levels converted into standardized scores within each cohort demonstrated statistically significant effects of condition (AA: $F_{2,37}=12.45 ; p<0.001$; DHA: $F_{2,37}=61.35 ; p<$ $0.001)$. For AA, post hoc comparisons indicated that infants fed supplemented formula exhibited higher plasma $z$-scored AA values than mother-reared infants and infants fed standard formula ( $p<0.01$ for both comparisons). Mother-reared infants did not differ significantly from infants fed standard formula. For DHA, mother-reared infants exhibited higher $z$ scores of plasma DHA than infants fed both formula types, and supplemented formula-fed infants exhibited higher values than standard formula-fed infants ( $p<0.001$ for all comparisons). Plasma AA and DHA levels (expressed as raw values, micrograms per milliliter) in the three conditions are depicted in Figures 1 and 2, respectively.

Neonatal assessment. There were statistically significant main effects for group, with infants fed the supplemented formula exhibiting higher scores than infants receiving the standard formula on the motor maturity cluster $\left(F_{1,21}=11.83\right.$; $p<0.01$; Fig. 3$)$ and on the orientation cluster $\left(F_{1,21}=5.10\right.$; $p<0.05$; Fig. 4). In addition, the analysis revealed a significant interaction of group and test day for the motor maturity cluster $\left(F_{3,62}=3.11 ; p<0.05\right)$, which indicated that group differences in motor maturity were most pronounced on test $\mathrm{d}$ 7 and 14. No group differences were detected on either the state control ( $p=0.38$; Fig. 5 ) or activity ( $p=0.51$; Fig. 6 ) clusters.

As in previous findings (47), significant effects of test day were obtained for the orientation cluster $\left(F_{3,62}=8.01 ; p<\right.$ $0.01)$, the motor maturity cluster $\left(F_{3,62}=6.48 ; p<0.01\right)$, and the activity cluster $\left(F_{3,62}=9.55 ; p<0.01\right)$. In all three clusters, scores increased as the subjects matured. No effect of test day was detected for the state control cluster.

Significant effects of cohort were demonstrated for the orientation cluster $\left(F_{2,21}=11.60 ; p<0.01\right)$ and for the motor

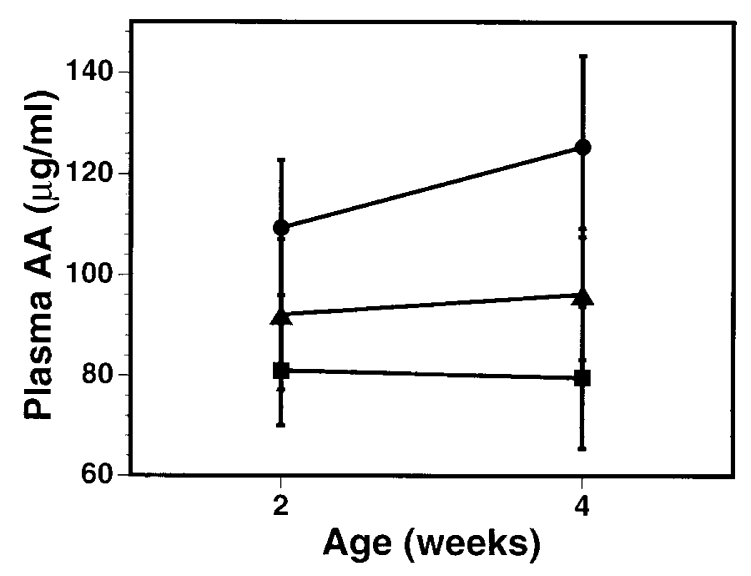

Figure 1. AA levels $(\mu \mathrm{g} / \mathrm{mL}$; mean \pm SEM $)$ in rhesus monkey infant plasma. Triangles, breast-fed infants ( $n=14)$; squares, infants fed standard formula ( $n$ $=14)$; circles, infants fed supplemented formula $(n=14)$. Graph depicts average across three cohorts. Infants fed supplemented formula exhibited higher AA values than breast-fed infants and infants fed standard formula. Mother-reared infants did not differ from infants fed standard formula $\left(F_{2,37}=\right.$ $12.45 ; p<0.001)$.

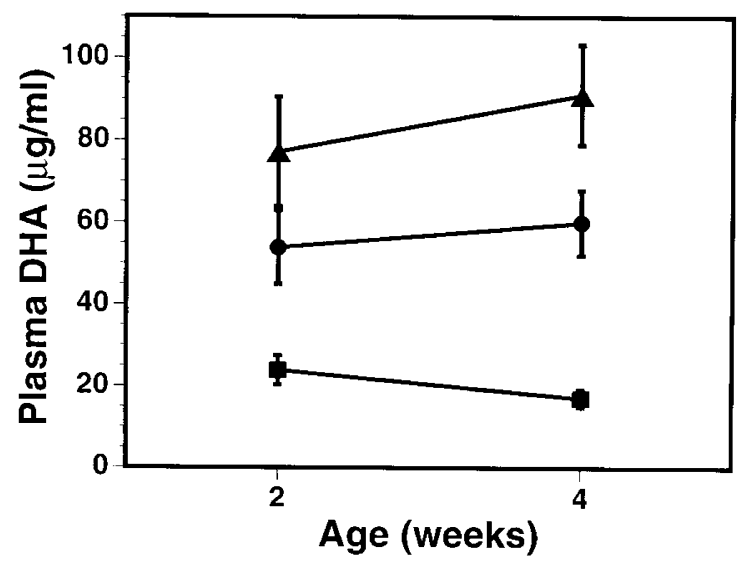

Figure 2. DHA levels $(\mu \mathrm{g} / \mathrm{mL}$; mean \pm SEM) in rhesus monkey infant plasma. Triangles, breast-fed infants $(n=14)$; squares, infants fed standard formula $(n=14)$; circles, infants fed supplemented formula $(n=14)$. Graph depicts average across three cohorts. Breast-fed infants exhibited higher levels of plasma DHA than infants fed both supplemented and unsupplemented formula, and supplemented formula-fed infants had higher levels than standard formula-fed infants $\left(F_{2,37}=61.35 ; p<0.001\right)$.

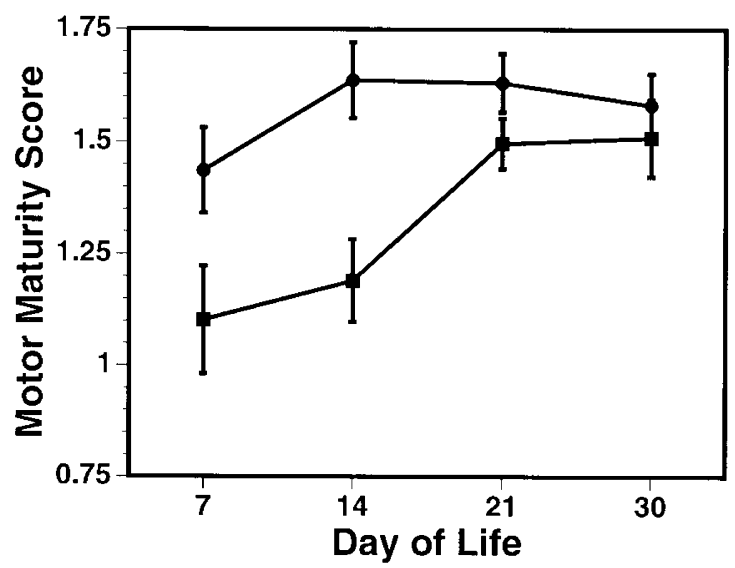

Figure 3. Motor maturity cluster (mean $\pm \mathrm{SEM}$ ) in rhesus monkey infants fed supplemented formula (circles, $n=14$ ) and standard formula (squares, $n$ $=13$ ). Graph depicts average across three cohorts. Infants fed supplemented formula exhibited higher scores than infants fed the standard formula $\left(F_{1,21}=\right.$ $11.83 ; p<0.01$ ), with differences being most pronounced on $\mathrm{d} 7$ and 14 (group $\times$ day interaction effect, $F_{3,62}=3.11 ; p<0.05$ ).

maturity cluster $\left(F_{2,21}=4.03 ; p<0.05\right)$. In both cases, cohort 3 animals exhibited lower scores than either cohorts 1 or 2; cohorts 1 and 2 did not significantly differ from each other. However, significant group by cohort effects were not obtained for either cluster. Cohort effects were not observed for either the state control $(p=0.07)$ or activity $(p=0.61)$ clusters. Table 4 depicts the cohort averages for each cluster.

\section{DISCUSSION}

Rhesus neonates consuming LC-PUFA-supplemented formula obtained higher scores on motor maturity and orientation items than infants receiving standard formula. Because these findings were most pronounced during $\mathrm{d} 7$ and 14 of life, and because these abilities typically improve during the first month of life using this assessment (55), our findings suggest an earlier maturation of specific visual and motor abilities in 


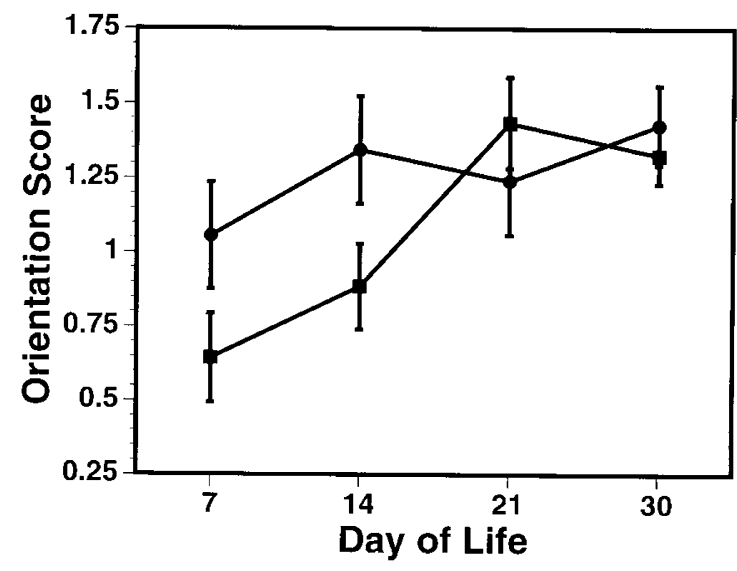

Figure 4. Orientation cluster (mean \pm SEM) in rhesus monkey infants fed supplemented formula (circles, $n=14$ ) and standard formula (squares, $n=$ 13). Graph depicts average across three cohorts. Infants fed supplemented formula exhibited higher scores than infants fed the standard formula $\left(F_{1,21}=\right.$ $5.10 ; p<0.05)$.

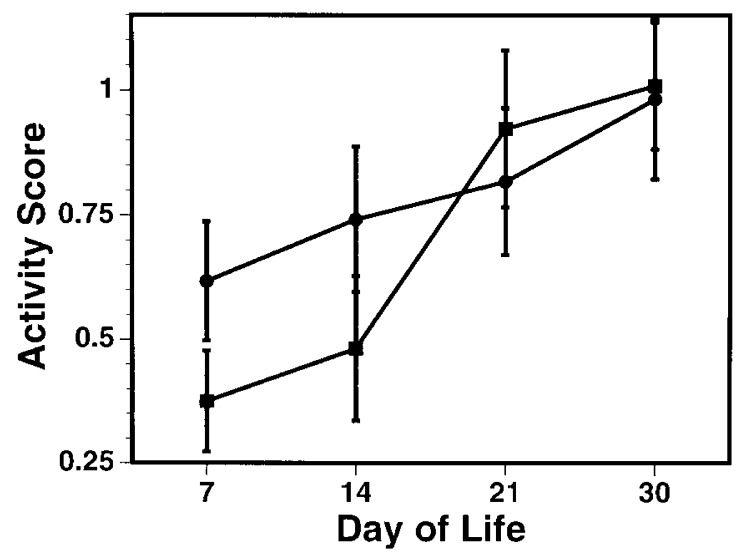

Figure 5. Activity cluster (mean \pm SEM) in rhesus monkey infants fed supplemented formula (circles, $n=14$ ) and standard formula (squares, $n=$ 14). Graph depicts average across three cohorts. No group differences were detected on this measure.

infants fed the supplemented formula. In human infants, differences in developmental quotient scores between LC-PUFAsupplemented and -unsupplemented 4-mo-old infants were noted, using a global neurodevelopmental assessment scale $(27,60)$. The results in human infants are consistent with the present findings: many of the Brunet-Lézine test items for 4-mo-old infants parallel those used in the primate examination (e.g. head posture, visual attention, and tracking). Additionally, the test ages of the subjects in the two studies are similar, as a 4-mo-old human infant is developmentally comparable to a 30 -d-old rhesus infant (61). It is noteworthy, however, that in studies comparing breast-fed and formula-fed human infants, there were no differences in orientation and motor scores on the NBAS $(62,63)$.

No effects of LC-PUFA supplementation were observed for the activity and state control clusters. In contrast to the orientation and motor maturity clusters, which assess specific visual or motoric skills, the activity and state control clusters reflect temperament and behavioral characteristics. In particular, two of the items in the activity cluster (passivity, spontaneous

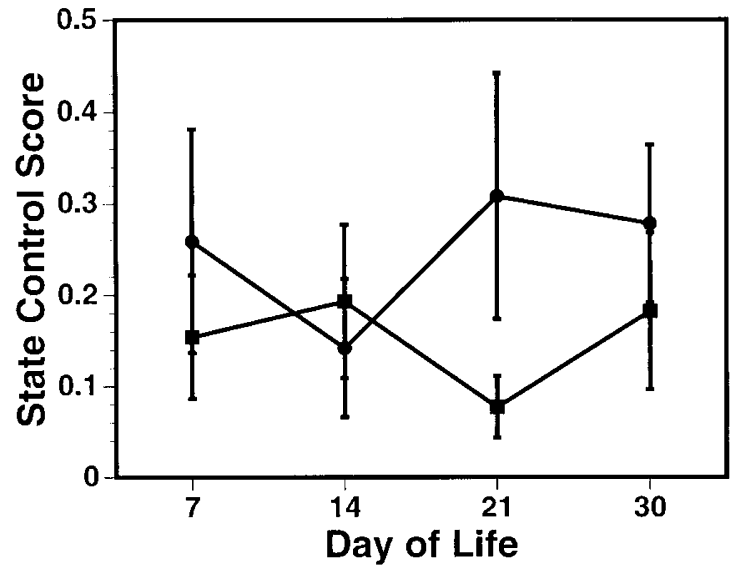

Figure 6. State control cluster (mean \pm SEM) in rhesus monkey infants fed supplemented formula (circles, $n=14$ ) and standard formula (squares, $n=$ 13). Graph depicts average across three cohorts. No group differences were detected on this measure.

Table 4. Cohort results for neonatal assessment clusters

\begin{tabular}{|c|c|c|c|}
\hline \multirow[b]{2}{*}{ Cluster } & \multicolumn{3}{|c|}{ Study cohort } \\
\hline & Cohort 1 & Cohort 2 & Cohort 3 \\
\hline Motor maturity* & $1.486 \pm 0.075$ & $1.577 \pm 0.049$ & $1.334 \pm 0.049$ \\
\hline Orientation* & $1.494 \pm 0.102$ & $1.282 \pm 0.107$ & $0.867 \pm 0.075$ \\
\hline State control & $0.097 \pm 0.035$ & $0.109 \pm 0.045$ & $0.338 \pm 0.061$ \\
\hline Activity & $0.806 \pm 0.098$ & $0.805 \pm 0.108$ & $0.656 \pm 0.072$ \\
\hline
\end{tabular}

Results are presented as mean \pm SEM

$* p<0.05$.

locomotion) measure the behavioral response to placement into an empty cage. Familiar attachment or comfort objects (inanimate surrogate, human caretaker, and fleece blankets) are absent or unobtainable during this portion of the examination, implying that the infant is undergoing an enforced separation experience. The nonhuman primate infant response to separation exhibits considerable individual variation, and is believed to be (at least partially) under genetic control. Although environmental factors can and do affect the behavioral response to separation (64), this usually occurs in response to profound manipulations such as rearing with mother versus rearing with peers. In contrast, less potent manipulations of the early rearing environment often fail to impact separation responses [e.g. controllable versus uncontrollable environments (65); adoption (66)]. Hence it is not surprising that environmental manipulations such as formula supplementation with LC-PUFA do not influence the response to separation.

The state control cluster represents the infant's emotional state during the assessment procedure. Although evidence indicates that breast-fed infants exhibit more distress than formula-fed infants during the NBAS (63) and during neonatal examinations $(67,68)$, this may reflect a disparity in breastfeeding and bottle-feeding styles and not LC-PUFA content of feeds per se (i.e. breast-fed infants require more frequent feedings and therefore may have been more hungry during examination). There is no direct evidence linking LC-PUFA intake with temperament characteristics in human neonates. In monkeys, as in humans, breast-fed (mother-reared) infants are fussier than bottle-fed (nursery-reared) infants. However, this 
contrast most likely reflects differences in infants' response to handling by humans rather than nutritional factors. The state control cluster also appears to possess substantial genetic underpinnings in rhesus monkeys: recent data (69) indicate the values for this cluster at 14 and $30 \mathrm{~d}$ of age exhibit modest, but statistically significant, heritabilities.

Examination of the data indicates that the differences between feeding conditions for both orientation and motor maturity items appeared most pronounced during test $\mathrm{d} 7$ and 14 . This pattern suggests an earlier maturation of specific visual and motor abilities in the supplemented infants. Because unsupplemented monkeys exhibited the expected maturational increase in motor maturity and orientation on d 21 and 30 (47), the disparity between groups was not as pronounced on those days. This ceiling effect represents a limitation of the test instrument. Although it is possible that the effects of LC-PUFA supplementation dissipate by the third week of life in the monkey infant, this cannot be determined without use of a more challenging or sophisticated instrument. It is plausible to consider that the persistent differences in plasma DHA and AA levels in supplemented and unsupplemented infants until 5 mo of age could potentially contribute to behavioral or cognitive differences between these groups between ages 1 and 5 mo.

Owing to time and space constraints it was only possible to study a limited number of animals in each year; hence the requirement to conduct the project in three cohorts. Furthermore, sufficient animal numbers were not available from one breeder to enable all infants to be obtained in one cohort. There is a possibility that there may have been genetic differences between cohort 1 and cohorts 2 and 3, which would influence our test outcome. Nonetheless, cohorts 1 and 2 did not differ significantly despite coming from different facilities. However, the marked differences in the infants' orientation and motor maturity scores in cohort 3 require explanation. We hypothesize that the lower scores of cohort 3 monkeys may in part reflect the outcome of unavoidable procedural differences in the third year of the study. Unlike cohorts 1 and 2, which were reared in dedicated nursery facilities, cohort 3 was raised for 4 to $11 \mathrm{~d}$ in a room containing monkeys of wide age ranges, including adults and groups of juveniles. Several infants received their $\mathrm{d} 7$ assessment in that location. In addition, many of the cohort 3 monkeys were tested on $\mathrm{d} 7$ and 14 in the morning immediately after overnight transport to the Poolesville facility. These testing conditions were clearly less than optimal. It should also be noted that although the comparison did not reach statistical significance $(p=0.07)$, the animals in cohort 3 exhibited a high value for the state control cluster, indicative of more distress, relative to the values for infants in cohorts 1 and 2. It is possible that the distress during the examination related to the lower orientation scores exhibited by y 3 infants. Previous studies (52) have demonstrated that high arousal levels during the examination are associated with low orienting abilities because of competing motor responses.

As expected, plasma concentrations of AA were higher in the group which consumed supplemented formula containing $1.0 \mathrm{wt} \% \mathrm{AA}$ in comparison to the group fed mother's milk that contained $0.2 \mathrm{wt} \% \mathrm{AA}$. We note that the plasma concentrations of AA in the mother-reared and standard formula groups did not differ although the standard formula contained only 0.04 wt $\%$ preformed AA. However, this result is consistent with the plasma concentrations in phospholipid predicted by the Lands equation (70) because the standard formula also contained relatively high concentrations of linoleic acid $(27.4 \mathrm{wt} \%)$ in comparison to $\alpha$-linolenic acid (2.0 wt\%). With little competition for elongation and desaturation from $\alpha$-linolenic acid and virtually no feedback inhibition from EPA and DHA (both nondetectable), plasma levels of AA were supported by linoleic acid at levels higher than expected by examining the amount of preformed AA alone. Supplementation of standard formula with $1.0 \mathrm{wt} \%$ DHA was not effective in equating plasma DHA levels in formula-fed infants with mother-reared infants. However, supplemented formula-fed infants exhibited higher plasma DHA concentrations than did infants fed standard formula.

In summary, our findings add to a growing body of evidence indicating a benefit in neurodevelopmental capabilities in infants fed LC-PUFA-supplemented formulas. Because all animals were reared in identical environments, and the only distinction between groups was in LC-PUFA availability, the differences in motor and visual functioning in this study can be directly and solely attributed to LC-PUFA intake. Future studies should address the effects of early divergence in LC-PUFA intake on developmental outcomes by using more extensive neurobehavioral test batteries, as well as assessments appropriate for older infants $(49,71-73)$.

Acknowledgments. The authors thank Wendy Airoso, Gwen Dube, and Margro Purple for their assistance in infant care and testing. Dr. Mary Schneider, University of Wisconsin, developed the neonatal assessment and trained Maribeth Champoux in its use. We also thank Jacqueline Fragard and Linda Siegel for obtaining the Brunet-Lézine manual for Maribeth Champoux; the National Institutes of Health Translating Service translated the manual from French to English (National Institutes of Health 98-348). Martek Biosciences Corporation (Columbia, MD, U.S.A.) supplied the formula supplement and provided financial support. The authors are grateful to three anonymous reviewers for their insightful comments.

\section{REFERENCES}

1. Farquharson J, Cockburn F, Patrick WA, Jamieson EC, Logan RW 1992 Infant cerebral cortex phospholipid fatty-acid composition and diet. Lancet 340:810-813

2. Farquharson J, Jamieson EC, Abbasi KA, Patrick WJA, Logan RW, Cockburn F 1995 Effect of diet on the fatty acid composition of the major phospholipids of infant cerebral cortex. Arch Dis Child 72:198-203

3. Jamieson EC, Farquharson J, Logan RW, Howatson AG, Patrick WJA, Weaver LT, Cockburn F 1999 Infant cerebellar gray and white matter fatty acids in relation to age and diet. Lipids 34:1065-1071

4. Makrides M, Neumann MA, Byard RW, Simmer K, Gibson RA 1994 Fatty acid composition of brain, retina, and erythrocytes in breast- and formula-fed infants. Am J Clin Nutr 60:1889-1894

5. Salem N Jr, Kim HY, Yergey JA 1986 Docosahexaenoic acid: membrane function and metabolism. In: Simopoulos AP, Kifer RR, Martin R (eds) The Health Effects of Polyunsaturated Fatty Acids in Seafoods. Academic Press, New York, pp 263-317

6. Carnielli VP, Wattimena DJL, Luijendijk IHT, Boerlage A, Degenhart HJ, Sauer PJJ 1996 The very low birth weight premature infant is capable of synthesizing arachidonic and docosahexaenoic acids from linoleic and linolenic acids. Pediatr Res 40:169-174

7. Salem Jr N, Wegher B, Mena P, Uauy R 1996 Arachidonic and docosahexaenoic acids are biosynthesized from their 18-carbon precursors in human infants. Proc Natl Acad Sci USA 93:49-54

8. Sauerwald TU, Hachey DL, Jensen CL, Chen HM, Anderson RE, Heird WC 1996 Effect of dietary alpha-linolenic acid intake on incorporation of docosahexaenoic and 
arachidonic acids into plasma phospholipids of term infants. Lipids 31(suppl):S131S135

9. Su H-M, Bernardo L, Mirmiran M, Ma XH, Corso TN, Nathanielsz PW, Brenna JT 1999 Bioequivalence of dietary $\alpha$-linolenic and docosahexaenoic acids as sources of docosahexaenoate accretion in brain and associated organs of neonatal baboons. Pediatr Res 45:87-93

10. Jensen RG 1996 The lipids in human milk. Prog Lipid Res 35:53-92

11. Cunnane SC, Francescutti V, Brenna JT, Crawford MJ 2000 Breast fed infants achieve a higher rate of brain and whole body docosahexaenoate accumulation than formula fed infants not consuming dietary docosahexaenoate. Lipids 35:105-111

12. Makrides M, Simmer K, Goggin M, Gibson RA 1993 Erythrocyte docosahexaenoic acid correlates with the visual response of healthy, term infants. Pediatr Res 33:425-427

13. Decsi T, Thiel I, Koletzko B 1995 Essential fatty acids in full term infants fed breast milk or formula. Arch Dis Child 72:F23-F28

14. Birch E, Birch D, Hoffman D, Hale L, Everett M, Uauy R 1993 Breast-feeding and optimal visual development. J Pediatr Opthalmol Strabismus 30:33-38

15. Lucas A, Morley R, Cole TJ, Gore SM 1994 A randomised multicentre study of human milk versus formula and later development in preterm infants. Arch Dis Child 70:F141-F146

16. Johnson DL, Swank PR, Howie VM, Baldwin CD, Owen M 1996 Breast feeding and children's intelligence. Psychol Rep 79:1179-1185

17. Horwood LJ, Fergusson DM 1998 Breastfeeding and later cognitive and academic outcomes. Pediatrics 101:9-20

18. Lucas A, Morley R, Cole TJ, Lister G, Leeson-Payne C 1992 Breast milk and subsequent intelligence quotient in children born preterm. Lancet 339:261-264

19. Lawrence PB 1994 Breast milk: best source of nutrition for term and preterm infants. Pediatr Clin North Am 41:925-941

20. Silva PA, Buckfield P, Spears GF 1978 Some maternal and child developmental characteristics associated with breast feeding: a report from the Dunedin Multidisciplinary Child Development Study. Aust Paediatr J 14:265-268

21. Jacobson SW, Jacobson JL 1992 Breastfeeding and intelligence. [letter] Lancet 339:745

22. Boehm G, Borte M, Böhles HJ, Müller H, Kohn G, Moro G 1996 Docosahexaenoic and arachidonic acid content of serum and red blood cell membrane phospholipids of preterm infants fed breast milk, standard formula or formula supplemented with n-3 and n-6 long-chain polyunsaturated fatty acids. Eur J Pediatr 155:410-416

23. Carlson SE, Ford AJ, Werkman SH, Peeples JM, Koo WWK 1996 Visual acuity and fatty acid status of term infants fed human milk and formulas with and without docosahexaenoate and arachidonate from egg yolk lecithin. Pediatr Res 39:882-888

24. Carlson SE 1996 Arachidonic acid status of human infants: influence of gestational age at birth and diets with very long chain n-3 and n-6 fatty acids. J Nutr 126:1092S$1098 \mathrm{~S}$

25. Birch EE, Garfield S, Hoffman DR, Uauy R, Birch DG 2000 A randomized controlled trial of early dietary supply of long-chain polyunsaturated fatty acids and mental development in term infants. Dev Med Child Neurol 42:174-181

26. Lucas A, Stafford M, Morley R, Abbott R, Stephenson T, MacFadyen U, Elias-Jones A, Clements H 1999 Efficacy and safety of long-chain polyunsaturated fatty acid supplementation of infant-formula milk: a randomised trial. Lancet 354:1948-1954

27. Agostoni C, Trojan S, Bellù R, Riva E, Giovanni M 1995 Neurodevelopmental quotient of healthy term infants at 4 months and feeding practice: the role of long-chain polyunsaturated fatty acids. Pediatr Res 38:262-266

28. Willatts P, Forsyth JS, DiModugno MK, Varma S, Colvin M 1998 Effect of long-chain polyunsaturated fatty acids in infant formula on problem solving at 10 months of age. Lancet 352:688-691

29. Werkman SH, Carlson SE 1996 A randomized trial of visual attention of preterm infants fed docosahexaenoic acid until nine months. Lipids 31:91-97

30. Carlson SE, Werkman SH 1996 A randomized trial of visual attention of preterm infants fed docosahexaenoic acid until two months. Lipids 31:85-90

31. Agostoni C, Trojan S, Bellù R, Riva E, Bruzzese MG, Giovanni M 1997 Developmental quotient at 24 months and fatty acid composition of diet in early infancy: a follow up study. Arch Dis Child 76:421-424

32. Carlson SE, Werkman SH, Rhodes PG, Tolley EA 1993 Visual-acuity development in healthy preterm infants: effect of marine-oil supplementation. Am J Clin Nutr 58:35-42

33. Birch DG, Birch EE, Hoffman DR, Uauy RD 1992 Retinal development in very low birth weight infants fed diets differing in omega-3 fatty acids. Invest Ophthalmol Vis Sci 33:2365-2376

34. SanGiovanni JP, Berkey CS, Dwyer JT, Colditz GA 2000 Dietary essential fatty acids, long-chain polyunsaturated fatty acids, and visual resolution acuity in healthy fullterm infants: a systematic review. Early Human Dev 57:165-188

35. SanGiovanni JP, Parra-Cabrera S, Colditz GA, Berkey CS, Dwyer JT 2000 Meta-analysis of dietary essential fatty acids and long-chain polyunsaturated fatty acids as they relate to visual resolution acuity in healthy preterm infants. Pediatrics 105:1292-1298

36. Carlson SE, Neuringer M 1999 Polyunsaturated fatty acid status and neurodevelopment: a summary and critical analysis of the literature. Lipids 34:171-178

37. Carlson SE 2000 Behavioral methods used in the study of long-chain polyunsaturated fatty acid nutrition in primate infants. Am J Clin Nutr 71:268S-274S

38. Auestad N, Montalto MB, Hall RT, Fitzgerald KM, Wheeler RE, Connor WE, Neuringer M, Connor SL, Taylor JA, Hartmann EE 1997 Visual acuity, erythrocyte fatty acid composition, and growth in term infants fed formulas with long chain polyunsaturated fatty acids for one year. Pediatr Res 41:1-10

39. Scott DT, Janowsky JS, Carroll RE, Taylor JA, Auestad N, Montalto MB 1998 Formula supplementation with long-chain polyunsaturated fatty acids: are there developmental benefits? Pediatrics 102:1203-1204(abstr)

40. Gibson RA, Makrides M 1999 Polyunsaturated fatty acids and infant visual development: a critical appraisal of randomized clinical trials. Lipids 34:179-184
41. Neuringer M, Connor WE, Lin DS, Barstad L, Luck S 1986 Biochemical and functional effects of prenatal and postnatal omega-3 fatty acid deficiency on retina and brain in rhesus monkeys. Proc Natl Acad Sci USA 83:4021-4025

42. Reisbick S, Neuringer M, Gohl E, Wald R, Anderson GJ 1997 Visual attention in infant monkeys: effects of dietary fatty acids and age. Dev Psychol 33:387-395

43. Reisbick S, Neuringer M, Hasnain R, Connor WE 1990 Polydipsia in rhesus monkeys deficient in omega-3 fatty acids. Physiol Behav 47:315-323

44. Reisbick S, Neuringer M, Hasnain R, Connor WE 1994 Home cage behavior of rhesus monkeys with long-term deficiency of omega-3 fatty acids. Physiol Behav 55:231-239

45. Young C, Hikita T, Kaneko S, Shimizu Y, Hanaka S, Abe T, Shimasaki H, Ikeda R, Miyazawa Y, Nakajima A 1997 Fatty acid compositions of colostrum, cord blood, maternal blood and major infant formulas in Japan. Acta Paediatr Jpn 39:299-304

46. Kanazawa A, Miyazawa T, Hirono H, Hayashi M, Fujimoto K 1991 Possible essentiality of docosahexaenoic acid in Japanese monkey neonates: occurrence in colostrum and low biosynthetic capacity in neonate brains. Lipids 26:53-57

47. Schneider ML, Suomi SJ 1992 Neurobehavioral assessment in rhesus monkey neonates (Macaca mulatta): developmental changes, behavioral stability, and early experience. Infant Behav Dev 15:155-177

48. Brazelton TB 1973 Neonatal Behavioral Assessment Scale (Clinics in Developmental Medicine, No. 50). William Heinemann Medical Books, London

49. Schneider ML, Moore CF, Suomi SJ, Champoux M 1991 Laboratory assessment of temperament and environmental enrichment in rhesus monkey infants (Macaca mulatta). Am J Primatol 25:137-155

50. Schneider ML 1992 The effect of mild stress during pregnancy on birthweight and motor maturation in rhesus monkey infants (Macaca mulatta). Infant Behav Dev 15:389-403

51. Schneider ML, Coe CL, Lubach GR 1992 Endocrine activation mimics the adverse effects of prenatal stress on the neuromotor development of the infant primate. Dev Psychobiol 25:427-439

52. Champoux M, Suomi SJ, Schneider ML 1994 Temperament differences between captive Indian and Chinese-Indian hybrid rhesus macaque neonates. Lab Anim Sci 44:351-357

53. Champoux M, Kriete MF, Eckhaus MA, Suomi SJ 1997 Behavioral and physical concomitants of congenital hydrocephalus in a rhesus macaque (Macaca mulatta) neonate. Contemp Top Lab Anim Sci 36:56-61

54. Ruppenthal GC 1979 Survey of protocols for nursery rearing infant macaques. In: Ruppenthal GC (ed) Nursery Care of Nonhuman Primates. Plenum Press, New York, pp $165-185$

55. Schneider ML 1987 A rhesus monkey model of human infant individual differences. Unpublished doctoral dissertation, University of Wisconsin-Madison

56. Folch J, Lees M, Sloane-Stanley GH 1957 A simple method for the isolation and purification of total lipids from animal tissues. J Biol Chem 226:497-509

57. Morrison WR, Smith LM 1959 Preparation of fatty acid methyl esters and dimethylacetals from lipids with boron-fluoride-methanol. J Lipid Res 5:600-608

58. Moriguchi T, Sheaf Greiner R, Salem N 2000 Behavioral deficits associated with dietary induction of decreased brain docosahexaenoic acid concentration. J Neurochem 75:2563-2573

59. LePage G, Roy CC 1986 Direct transesterification of all classes of lipids in a one-step reaction. J Lipid Res 27:114-120

60. Brunet O, Lézine I 1966 Le Développement Psychologique de la Première Enfance, 2nd Ed. Presses Universitaires de France, Paris

61. Golub MS, Gershwin ME 1984 Standardized neonatal assessment in the rhesus monkey. In: Nathanielz PW, Parer JT (eds) Research in Perinatal Medicine. Perinatology Press, Ithaca NY, pp 55-86

62. Chan GM, Borschel MW, Jacobs JR 1994 Effects of human milk or formula feeding on the growth, behavior, and protein status of preterm infants discharged from the newborn intensive care unit. Am J Clin Nutr 60:710-716

63. DiPietro JA, Larson SK, Porges SW 1987 Behavioral and heart rate pattern differences between breast-fed and bottle-fed neonates. Dev Psychol 23:467-474

64. Mineka S, Suomi SJ 1978 Social separation in monkeys. Psychol Bull 85:1376-1400

65. Mineka S, Gunnar M, Champoux M 1986 Control and early socioemotional development: infant rhesus monkeys reared in controllable versus uncontrollable environments. Child Dev 57:1241-1256

66. Champoux M, Boyce WT, Suomi SJ 1995 Biobehavioral comparisons between adopted and nonadopted rhesus monkey infants. J Dev Behav Pediatr 16:6-13

67. Bell RQ 1966 Level of arousal in breast-fed and bottle-fed human newborns. Psychosom Med 28:177-180

68. Bernal J, Richards MPM 1970 The effects of bottle and breast feeding on infant development. J Psychosom Res 14:247-252

69. Champoux M, Jaquish CE, Higley SB, Suomi SJ 1999 Heritability of standardized biobehavioral assessment scores in rhesus monkey infants. Am J Primatol 49:42(abstr)

70. Lands WEM, Libelt B, Morris A, Kramer NC, Prewitt TE, Bowen P, Schmeisser D, Davidson MH, Burns JH 1992 Maintenance of lower proportions of (n-6) eicosanoid precursors in phospholipids of human plasma in response to added dietary (n-3) fatty acids. Biochim Biophys Acta 1180:147-162

71. Schneider ML 1992 Delayed object permanence development in prenatally stressed rhesus monkey infants (Macaca mulatta). Occup Ther J Res 12:96-110

72. Burbacher TM, Gunderson VM, Grant-Webster KS, Mottet NK 1990 Methods for assessing neurobehavioral development during infancy in primates. In: Johnson BL (ed) Advances in Neurobehavioral Toxicology: Applications in Environmental and Occupational Health. Lewis Publishers, Chelsea, MI, pp 449-454

73. Ruppenthal GC, Sackett GP 1992 Research Protocol and Technician's Manual: A Guide to the Care, Feeding, and Evaluation of Infant Monkeys, 2nd Ed. IPRL, University of Washington, Seattle WA 